\title{
The Effects of the Media on Self-Esteem of Young Girls
}

\author{
Róbert Osad'an - Rania Hanna*
}

\begin{abstract}
There have been a number of studies investigating the media's role in body image dissatisfaction, eating disorders, self-esteem, and the internalization of the thin body ideal in young girls and women. However, much of the research focuses on girls ages 10 and older; very few examine those girls of pre-primary or primary age. This paper seeks to explore the studies that do focus on the younger age groups, and understand the relationship between the media and young girls' self-esteem.
\end{abstract}

Key words: body dissatisfaction, eating disorders, girls, media, selfesteem.

\section{Introduction}

Young girls are becoming increasingly aware of their body image through the image of models in advertising, and image-centered ideals portrayed in the media. A number of studies have been developed in the past several years that have determined that the media does indeed have negative influences on young girls' self-esteem, body-image, and ideas of self-worth. Further, these experiences and influences can impact girls and drive them towards behaviors that are unhealthy, including eating disorders. This paper seeks to review the literature and consolidate findings in a systematic and thorough capacity.

Weight is a sensitive issue among many girls and young women. Specifically, younger girls are showing a concern for body image and weight at alarmingly young ages, including as young as age 5. Some of these girls are at healthy weights, others are overweight. Of course, weight has an impact on a girl's selfesteem, with those even as young as 5 years reporting lower body self-esteem, and lower perceived intelligence if they were of a higher weight (Davison and

* Róbert Osad'an, Comenius University in Bratislava, Bratislava, Slovakia; osadan@fedu.uniba.sk

Rania Hanna, Moravian College, Bethlehem Pa, USA; rhanna0308@gmail.com 


\section{Acta Technologica Dubnicae \\ volume 5, 2015, issue 1}

Birch, 2000). Regardless, peer influences and the media have a profound impact on a young girl's self-esteem, and her body-image ideals, which can lead to unhealthy behaviors and emotional/mental states.

\section{Discussion}

Even brief exposure to seeing skinny models leads to body dissatisfaction. In one study, 210 adolescent girls were randomly assigned to a 15-month fashion magazine subscription, or no-subscription condition (Stice, Spangler and Argas, 2001). The researchers followed these girls over time, and determined that, interestingly, there were no long-term negative effects of being exposed to fashion magazines. That is, there were no long-term effects related to the thinideal internalization, body dissatisfaction or eating disorders. However, it was found that vulnerable adolescents, who had initial perceptions of the "thin-ideal" and who did not have proper social support, were negatively impacted by exposure to the thin-model images. Therefore, exposure to thin-ideal model images had lasting negative effects on vulnerable young girls.

A study that examined 97 girls aged 5-8 determined that watching appearancethemed/focused television program was an antecedent to appearance satisfaction (Dohnt and Tiggemann, 2006a). That is, watching these television programs had a direct, and oftentimes negative, effect on these young girls' self-esteem. Alarmingly, as young as school-age children just beginning their education, girls are already vulnerable to, and live in a culture, where the media transmits body image ideals, include thinness, which negatively impacts these young girls' selfesteem, and influences the development of their body image.

Another study by these researchers recruited 128 girls, aged 5-8 (Dohnt and Tiggemann, 2006b). The researchers determined that by age 6 , many of these girls wanted to be slimmer, and thought that thinness was the ideal figure to have. The media and peer influences were indicated to be the driving factors behind these girls' desires to have a thinner body, and the consequent dieting schemas that arise from such desires. Dieting awareness was predicted by the girls' viewing of music television shows (which often feature thin models), and reading appearance-themed magazines.

These two studies have determined that young girls, aged 5-8, are already aware of body image ideals, and have desires driven by a culture that showcases appearance and images.

Field, Camargo, Taylor, Berkey, Roberts and Colditz (2001) determined that young girls, aged 9-14, become highly concerned with their weight. Regardless of their age or body mass index (BMI), girls who made strong efforts to look like women in the media were more likely to be concerned about their weight. Therefore, the media does have a strong influence on the development of girls' weight worries. 


\section{Acta Technologica Dubnicae \\ volume 5, 2015, issue 1}

Harrison and Hefner (2006) found that media exposure can lead to eating disorders among girls (and young women). The media exposure causes these young girls to internalize a thin-body ideal, which then leads to the girls desire to be thin. 257 preadolescent girls were examined. It was found that specifically, television-viewing predicted eating disorder and a thinner body-ideal. However, post-pubescence, when these girls were also examined, were not as predictable in terms of eating disorders and television exposure.

A study that examined 791 girls determined that the internalization of media body ideals led to girls being dissatisfied with their bodies (Knauss, Paxton and Alsaker, 2007). In fact, in these young girls, the strongest predictor for body dissatisfaction was the internalization of body ideals from the media.

Highly attractive models in advertising impacts female pre-adolescents and adolescents. Girls in grades four, six and eight were studied, and it was found that social comparison was a big factor that drove the girls' body image, in relation to media exposure (Martin and Gentry, 1997). However, the social comparison theory was not consistent across all grade groups, and there are therefore other factors that impact a girl's self-esteem, in relation to being exposed to highly attractive models in the advertising that they are viewing.

Appearance schemas are a cognitive component of body image. Appearance schemas are associated with pre-adolescent girls' levels of depression and their concern with their weight (Sinton and Birch, 2006). Furthermore, these appearance schemas made these young girls more aware of media messages related to female appearance. They were also related to the girls' dissatisfaction with their bodies. It seems here that being susceptible already to body dissatisfaction made the girls more aware, and more vulnerable, to the messages and effects of the media on the development of how they perceive themselves, other girls, and how much importance they place on their appearance. It may be that the media is certainly a risk factor for negative body image, but that the media may be more so a causal risk factor (Levine and Murnen, 2009).

One hundred girls aged 9-12 completed questionnaires about media exposure, which included magazines and television, internalization, and body dissatisfaction (Clark and Tiggeman, 2006). The girls' height and weight were measured; nearly half of these girls expressed a desire to be thinner. The girls' exposure to the appearance-focused media, outlets were not directly related to the girls' body dissatisfaction, but rather they were indirectly related through the conversations about appearance that they had with their peers. These appearance-themed conversations with peers had a significant relationship with the girls' internalization of thin body ideals, which, not surprisingly, led to their body dissatisfaction.

Caucasian girls are not the only ones affected by body dissatisfaction and dieting. Preadolescent British Asian girls have been found to be just as susceptible to eating disorders as their Caucasian counterparts (Hill and Bhatti, 1995). Both Asian and Caucasian girls placed an emphasis on thinness. Further, 


\section{Acta Technologica Dubnicae \\ volume 5, 2015, issue 1}

it was found in the Asian samples an association between dieting and the cultural aspects of their family. Therefore, the desire to be thinner seems to be a combination of socio-cultural influences, and may have a strong influence on the development of eating disorders in young girls.

One study that looked at 121 girls between the ages of 3-6 (Hayes and TantleffDunn, 2010). The researchers examined the effects of brief exposure to appearance-themed media on the girls' body image. What was interesting was that there was no effect found of media on body dissatisfaction. It may be, the researchers hypothesized, that younger children, as opposed to older individuals, adopt the persona of the characters deemed attractive, rather than comparing themselves to the characters. However, though nearly one-third of the girls were fine with their appearance nearly half of the girls were worried about being fat. Their exposure to the appearance-themed media did not seem to worsen their concerns.

The Barbie doll has been viewed with concern over the last number of years. In one study, Barbie dolls were examined as a possible factor in the body dissatisfaction of young girl aged 5-8 (Dittmar, Halliwell and Ive, 2006). These young girls were exposed to Barbie dolls, Emme dolls, which are a U.S. size 16, or no dolls conditions. The girls then completed body image assessments. It was found that the young girls exposed to Barbie reported a lower self-esteem, and an increased desire to be thin, compared to girls in the other conditions. However, in the older girls, this Barbie doll effect was not present. Therefore, it seems that the dolls are no longer models for older girls, but that it may be important to limit younger girls' exposure to Barbie dolls to prevent them from wanting to attain an unrealistically thinner body. Therefore, the media of playthings and the Barbie franchise may be something that should be limited to younger girls, who may be more vulnerable to the ideals presented by the dolls' unrealistic body proportions and appearance.

Barbie dolls are not the only children's character that may contribute to body dissatisfaction.

A content analysis examined body image-themed messages in children's videos and books (Herbozo, Tantleff-Dunn, Gokee-Larose and Thompson, 2004). It was determined that it was not so much the books that were an issue, but rather, the videos. In these videos, physical appearance was emphasized as being of importance. The analysis examined a number of videos, but the ones that most exhibited body and appearance themed messages were The Little Mermaid and Cinderella. Cinderella is portrayed as being thin and beautiful. The children complain about their body shape and size, and many indicate they wished they were thinner and prettier. Of the books examined, Rapunzel was found to have the most appearance-related themes. These do affect children's ideals and do develop a child's awareness of physical appearance as being important, which does lead to body dissatisfaction. Specifically, the children's stories catapult a desire for thinness that are unhealthy in these young children. 


\section{Acta Technologica Dubnicae \\ volume 5, 2015, issue 1}

Pine (2001) studied 140 children, aged 5-11, and explored what these children thought was the ideal shape for an adult male and female, and whether the shapes were related to masculinity or femininity. Both girls and boys agreed on what was considered the ideal male body. However, there was disagreement on what the ideal female shape was, even as young as 5 years of age. The figure chosen by girls was significantly thinner than the figure chosen by the boys. The girls also indicated wanting a thinner body. Girls aged 9, regardless of BMI, indicated they were dieting. Stereotypically feminine traits were associated with the thinner female body shape, than a heavier one. Masculine traits were not associated with any one male body shape. Therefore, the children believed that to be feminine, one must be thin, but to be masculine, body weight and shape did not matter as much. There are implications related to the development of eating disorders in response to these patterns of thinking, where girls are more likely to develop such disorders while aspiring to be considered feminine.

Interestingly, but not surprisingly, television viewing among first to third grade children resulted in fat stereotyping and the standardization of body shapes and sizes (Harrison, 2000). Among the boys in the study who were surveyed, it was determined by the researchers that fat females were stereotyped. In not just girls, but also boys, there could also be predicted the development of eating disorders. Interestingly, interpersonal attraction to thinner television characters was not predictive of thin-ideal behaviors, but interpersonal attraction to average-weight characters had a negative effect on the young female girls surveyed in the study.

\section{Conclusions}

Many of these studies are alarming, and indicate a great need for education and awareness on the effects of the media on children, especially younger girls in terms of body imagery. It is not just peers that determine how healthy a young girl is psychologically in relation to her body; it is the ever-present media, television shows, ads, even the toys and stories that children are exposed to have negative effects on vulnerable girls. There can be strategies implemented, that include lessening the exposure of these girls to the media. However, the media is everywhere, and their presence cannot be controlled. What can be more controlled are the ways the media portrays female characters, the way females of different body shapes are stereotyped, or not, and the way the media connects physical attractiveness with worth and value. The media have the power to shift the perspectives of these young, vulnerable girls, by approaching beauty and thinness in healthier capacities.

Of course, the media cannot be blamed for everything. We must realize that the media is only one factor that influences how a girl perceives herself and her body. Parents and those in positions of authority over children, like teachers and counselors, can do much to help a girl boost her self-esteem. Parents can approach their children in healthy ways that include not fat-shaming others or 


\section{Acta Technologica Dubnicae \\ volume 5, 2015, issue 1}

their children, and instead focusing on having the child eat healthy and stay physically active. Teaching a girl to live by her own rules and empowering her, rather than being controlled by the messages of the media, can go a long way in helping a girl grow comfortable in her own body.

All this requires empathy and a connection to the child. A loving environment that supports and teaches a girl to recognize her worth in her goals, and gives her the self-empowerment to achieve those goals can help her gain a self of selfworth, and move away from identifying herself with just the way she looks. Coviewing, with parents watching television with their children, and encouraging their child to think critically about what is being viewed, can go a long way in helping to sustain and preserve a girl's self-esteem. Girls must have a strong foundation for being able to see past the images and build for themselves a view of their body, attractiveness, and worth away from thin ideals, fat stereotyping, and the disorders that body dissatisfaction can lead to.

\section{References}

BLOWERS, L. C., LOXTON, N. J., GRADY-FLESSER, M., OCCHIPINTI, S., and DAWE, S. The relationship between sociocultural pressure to be thin and body dissatisfaction in preadolescent girls. Eating Behaviors, 4, 2003, 3, pp. 229-244.

CLARK, L., and TIGGEMENN, M. Appearance Culture in Nine-to 12-Year-Old Girls: Media and Peer Influences on Body Dissatisfaction. Social Development. [online]. 15, 2006, 4, pp. 628-643. Available from: $<$ http://onlinelibrary.wiley.com/doi/10.1111/j.1467-9507.2006.00361.x/ abstract;jsessionid=00C8CAB3C8879E3AEEF252B95731 AD64.f04t03?denied AccessCustomisedMessage $=\&$ userIs Authenticated $=$ false $>$ DAVISON, K. K., and BIRCH, L. L. Weight status, parent reaction, and selfconcept in five-year-old girls. Pediatrics. [online]. 107, 2001, 1, pp. 46-53. Available from: $<$ http://pediatrics.aappublications.org/content/107/1/46.short $>$ DITTMAR, H., HALLIWELL, E., and IVE, S. Does Barbie make girls want to be thin? The effect of experimental exposure to images of dolls on the body image of 5-to 8-year-old girls. Developmental psychology, 42, 2006, 2.

DOHNT, H. K., and TIGGEMANN, M. Body image concerns in young girls: The role of peers and media prior to adolescence. Journal of Youth and Adolescence. [online]. 35, 2006b, 2, pp. 135-145. Available from: $<$ http://link.springer.com/article/10.1007/s10964-005-9020-7\#page-1>

DOHNT, H., and TIGGEMANN, M. The contribution of peer and media influences to the development of body satisfaction and self-esteem in young girls: a prospective study. Developmental psychology. [online]. 42, 2006a, 5, p. 929. Available from: <http://psycnet.apa.org/journals/dev/42/5/929/>

FIELD, A. E., CAMARGO, C. A., TAYLOR, C. B., BERKEY, C. S., ROBERTS, S. B., and COLDITZ, G. A. Peer, parent, and media influences on 


\section{Acta Technologica Dubnicae \\ volume 5, 2015, issue 1}

the development of weight concerns and frequent dieting among preadolescent and adolescent girls and boys. Pediatrics. [online]. 107, 2001, 1, pp. 54-60. Available from: $<$ http://pediatrics.aappublications.org/content/107/1/54.short $>$ HARRISON, K., and HEFNER, V. Media exposure, current and future body ideals, and disordered eating among preadolescent girls: A longitudinal panel study. Journal of Youth and Adolescence. [online]. 35, 2006. 2, pp. 146-156. Available from:

$<$ http://link.springer.com/article/10.1007/s10964-005-9008-3\#page-1>

HAYES, S., and TANTLEFF-DUNN, S. Am I too fat to be a princess? Examining the effects of popular children's media on young girls' body image. British Journal of Developmental Psychology, 28, 2010, 2, pp. 413-426.

HERBOZO, S., TANTLEFF-DUNN, S., GOKEE-LAROSE, J., and THOMPSON, J. K. Beauty and thinness messages in children's media: A content analysis. Eating Disorders, 12, 2004, 1, pp. 21-34.

HILL, A. J., and BHATTI, R. Body shape perception and dieting in preadolescent British Asian girls: Links with eating disorders. International Journal of Eating Disorders. [online]. 17, 1995, 2, pp. 175-183. Available from: $<$ http://onlinelibrary.wiley.com/doi/10.1002/1098108X(199503)17:2\%3C175::AID-EAT2260170211\%3E3.0.CO;2-6/full> KNAUSS, C., PAXTON, S. J., and ALSAKER, F. D. Relationships amongst body dissatisfaction, internalisation of the media body ideal and perceived pressure from media in adolescent girls and boys. Body Image. [online]. 4, 2007, 4, pp. 353-360. Available from:

$<$ http://www.sciencedirect.com/science/article/pii/S1740144507000721>

LEVINE, M. P., and MURNEN, S. K. "Everybody knows that mass media are/are not [pick one] a cause of eating disorders": A critical review of evidence for a causal link between media, negative body image, and disordered eating in females. Journal of Social and Clinical Psychology. [online]. 28, 2009, 1, pp. 942. Available from:

$<$ http://guilfordjournals.com/doi/abs/10.1521/jscp.2009.28.1.9>

MARTIN, M. C., and GENTRY, J. W. Stuck in the model trap: The effects of beautiful models in ads on female pre-adolescents and adolescents. Journal of Advertising. [online]. 26, 1997, 2, pp. 19-33. Available from:

$<$ http://www.tandfonline.com/doi/abs/10.1080/00913367.1997.10673520\#.VBo nNfldVCc $>$

MILKIE, M. A. Social comparisons, reflected appraisals, and mass media: The impact of pervasive beauty images on Black and White girls' selfconcepts. Social Psychology Quarterly. [online]. 1999, pp. 190-210. Available from: $\quad<$ http://www.jstor.org/discover/10.2307/2695857?uid=3739256\&uid= 2\&uid $=4 \&$ sid $=21104643331297>$

PINE, K. J. Children's perceptions of body shape: A thinness bias in preadolescent girls and associations with femininity. Clinical Child Psychology and Psychiatry. [online]. 6, 2001, 4, pp. 519-536. 


\section{Acta Technologica Dubnicae \\ volume 5, 2015, issue 1}

SINTON, M. M., and BIRCH, L. L. Individual and sociocultural influences on pre-adolescent girls' appearance schemas and body dissatisfaction. Journal of Youth and Adolescence. [online]. 35, 2006, 2, pp. 157-167. Available from: $<$ http://link.springer.com/article/10.1007/s10964-005-9007-4\#page-1>

SMOLAK, L. Body image in children and adolescents: where do we go from here? Body image. [online]. 1, 2004, 1, pp. 15-28. Available from:

$<$ http://www.sciencedirect.com/science/article/pii/S1740144503000081>

STICE, E., SPANGLER, D., and AGRAS, W. S. Exposure to media-portrayed thin-ideal images adversely affects vulnerable girls: A longitudinal experiment. Journal of Social and Clinical Psychology. [online]. 20, 2001, 3, pp. 270-288. Available from:

$<$ http://guilfordjournals.com/doi/abs/10.1521/jscp.20.3.270.22309>

Harrison, K. 2000. Television viewing, fat stereotyping, body shape standards, and eating disorder symptomatology in grade school children. Communication Research, 27, 2000, 5, pp. 617-640. 